\title{
Embedded based Industrial Temperature Monitoring Systems using GSM
}

\author{
T. Murugan \\ Project Fellow DST-PURSE \\ Department of Electronics and \\ Instrumentation \\ Bharathiar University \\ Coimbatore
}

\author{
Azha.Periasamy \\ Assistant Professor \\ Department of Electronics and \\ Instrumentation \\ Bharathiar University \\ Coimbatore
}

\author{
S. Muruganand, Ph.D \\ Assistant Professor \\ Department of Electronics and \\ Instrumentation \\ Bharathiar University \\ Coimbatore
}

\begin{abstract}
This paper describes the design of a simple low cost microcontroller based temperature monitoring system using GSM technique. The temperature monitoring system using GSM undergoes three stages signal conditioning circuit, analog to digital converter and with GSM Modem the message is send to mobile.ADC is used because microcontroller works with digital inputs. GSM modem can be used to send and receive SMS through AT commands. At the transmitter side, the user sends an SMS to the GSM modem using AT commands. The LM35 is an integrated circuit sensor that can be used to measure temperature with electrical output proportional to the temperature. The LM35 sensor is connected to PIC microcontroller and varying temperature is sent to GSM modem, which is simultaneously displayed in LCD. The GSM modem performs the operation of sending message to a particular SIM number .GSM technology provides users with high quality signal and speech channels, giving them access to high quality digital communication at very affordable rates. GSM network operators can provide their customers with cheaper calling and text messing options.
\end{abstract}

\section{Keywords}

GSM, SMS, Temperature, Micro Controller, LM35, GSM modem

\section{INTRODUCTION}

The objective of this paper is to design and develop a wireless communication link to monitor and control equipments that are far away from the user and also develop a high security system to keep a check on them. In an industry during certain hazards it will be very difficult to monitor the parameter through wires and analog devices such as transducers. Embedded system plays a vital role in this paper. It is a user-friendly application system. GSM plays a key role for transmitting and receiving the data from the user. The main advantage of this concept is the real time direct measurement of the parameter through GSM technique. The stoppage and some accidents caused by increased temperature can be avoided. The self designed GSM module is selected to finish the transmission and decoding of the data through "AT " command and coding of short PDU. Here, the temperature is monitored directly which is simultaneously displayed in the LCD and can be sent as a message by GSM technique.

\section{GSM}

Global System for Mobile Communications or GSM (originally from Groupe Spécial Mobile), is the world's most popular standard for mobile telephone systems. The GSM Association estimate that $80 \%$ of the global mobile market uses the standard A GSM modem is a wireless modem that works with a GSM wireless network [1].Global Positioning System is one of the widely used mobile standards. As the name specifies, it enables the mobile users to interact all over the world at any time [4]. It is a hardware component that allows the capability to send and receive SMS to and from the system. The communication with the system takes place via RS232 serial port. Cell phone can be attached at the place of GSM hardware but it limits the hardware functionality such as sending or receiving of SMS [2]. GSM services include telephony, asynchronous and synchronous data services $(2.4 / 4.8 / 9.6 \mathrm{Kbps})$, value added features (SMS, fax) and more. Speech is digitally encoded and transmitted as digital stream standards. 


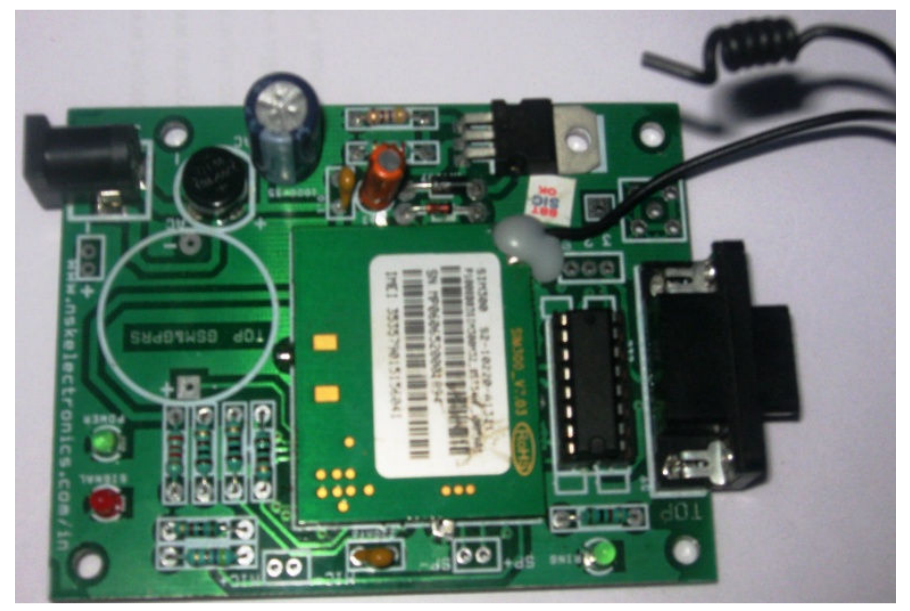

Fig 1: GSM module i.e. SIM 300

GSM users can send and receive data, at rates up to 9,600 bps [3]. The dominant mobile phone network in the world today is GSM. It is a digital mobile communication network, which developed, rapidly in recent years. This network has coverage in most urban areas and offer support for the SMS [5].

\subsection{SIM300}

The SIM300 is a complete Tri-band GSM solution in a compact plug-in module [14][15].The GSM modem consist of SIM card named as a SIM 300 is fixed with the modem. The SIM300 offers GSM/GPRS for performing operations like voice, SMS, Data and also Fax. It is small in size to handle easily and perfectly in any device. AT commands also can be easily used because it has a TTL interface with microcontrollers, computers and also other device. AT commands are used to send and received SMS. SIM300 works with $3.4 \mathrm{~V}$ to $5 \mathrm{~V}$.

\section{AT COMMENTS [11]}

AT + CSMS - Select short message service

$\mathrm{AT}+\mathrm{CMGF}-$ Set short message service mode ( 1 for text mode , 0 for PDU mode)

$\mathrm{AT}+\mathrm{CMGS}-$ Sent short message

AT + CSCA - Short message service number.

\section{PRINCIPLE}

As GSM is the main objective, the temperature which is continuously monitored by using temperature sensor exceeds a particular level the SMS is sent to particular mobile as an indication for avoiding damage or accidents. This operation is processed by PIC microcontroller in which the program written in Embedded $\mathrm{C}$ is dumped into it. It is thus referred as precaution for avoiding damage and alert given to persons by sending message to mobiles.

\section{SOFTWARE}

The program is written in Embedded $\mathrm{C}$ in MPLAB IDE. MPLAB Integrated Development Environment (IDE) is an integrated toolset for the development of embedded application employing Microchip's PIC and PIC microcontroller [13]. The compile tool is CCS (Custom Computer Service) used to convert C Language to HEX File. The HEX file is dumped into the PIC microcontroller using super pro $580 \mathrm{u}$. All the code is design for project we are used MPLAB IDE Tools V8.70. [12].

\section{HARDWARE}

\subsection{Temperature Sensor (LM35)}

LM35 is a sensor is used to sense the temperature. The temperature received in the output of LM35 does not need any further calibration or any other functions and also it draws only 60 micro amps from its supply. The operating temperature range is from $-55^{\circ} \mathrm{C}$ to $150^{\circ} \mathrm{C}$. The output voltage varies by $10 \mathrm{mV}$ in response to every ${ }^{\circ} \mathrm{C}$ rise/fall in ambient temperature, i.e., its scale factor is $0.01 \mathrm{~V} /$ degree $\mathrm{C}$.

\subsection{Microcontroller}

The microcontroller used is PIC 16F877A. The program on the microcontroller, reads the value of the temperature. The micro controller programming is done using Embedded C, a middle level language for control units. The PIC microcontroller PIC 16F877A has an operating speed Max 20 MHZ, voltage $(2-5.5 \mathrm{v})$. Memory consists of flash program RAM, EEPROM and Data Memory [7]. Displayed data of temperature are transferred to RS 232, which is interfaced with microcontroller through MAX232 [6]. 


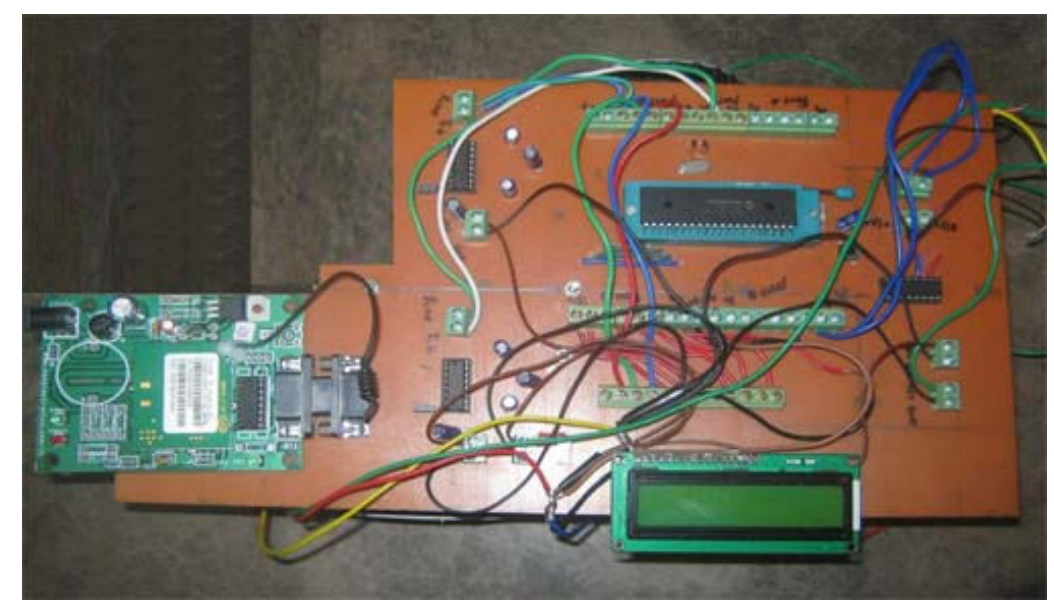

Fig 2: Hardware Setup

\section{WORKING}

The LM 35 is the temperature sensor connected to AN0 port of the PIC microcontroller device. The output voltage of the sensor is obtained in milli volt and it amplified by using
IC741. The GSM modem and LCD are connected to PIC microcontroller. The temperature can be monitored directly which is simultaneously displayed in the LCD and sends as a message to the mobile by using GSM technique.

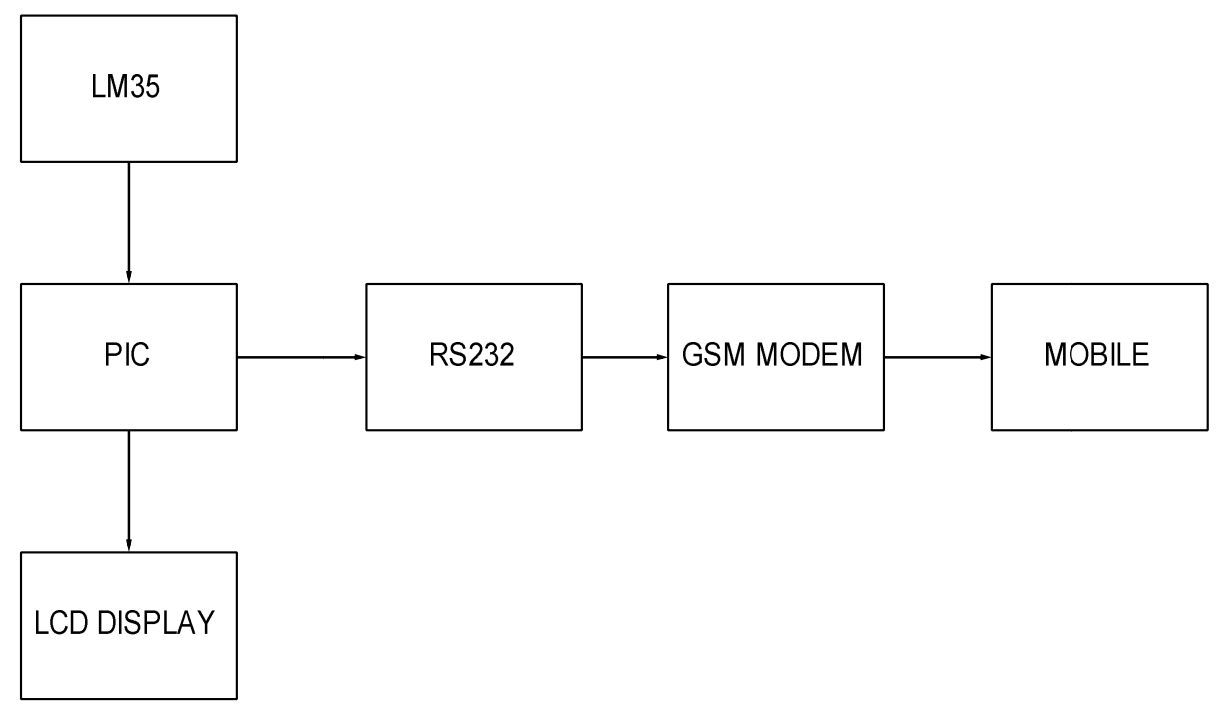

Fig 3: Block diagram

\subsection{CIRCUIT DIAGRAM}

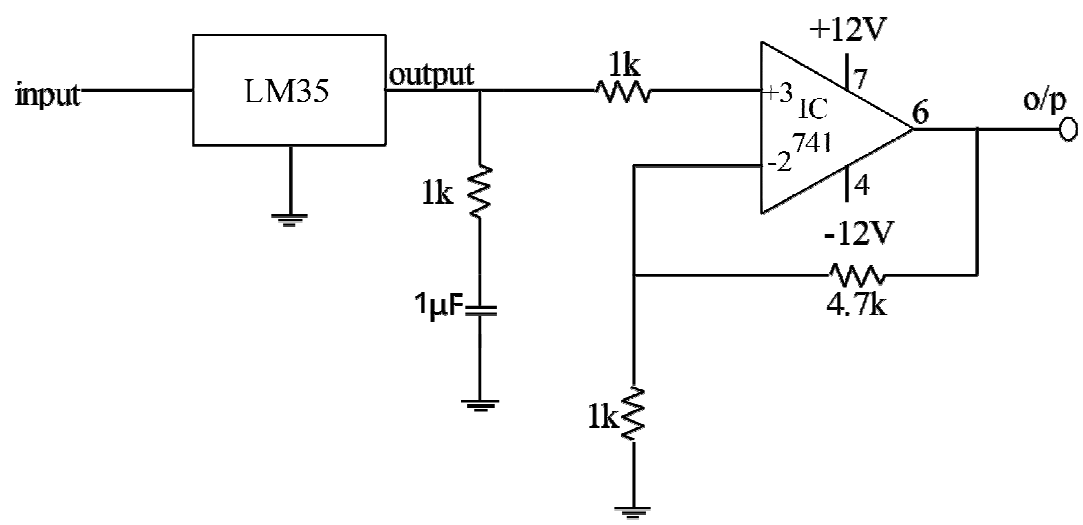

Fig 4: Amplification circuit for LM 35 using IC741 
LM35 produces $10 \mathrm{mV}$ per degree ${ }^{\circ} \mathrm{C}$ [9]. The microcontroller required the input volt for $\mathrm{ADC}$ port is $0 \mathrm{~V}$ to $5 \mathrm{~V}$. The output voltage of temperature sensor is $100^{\circ} \mathrm{C}=1 \mathrm{~V}$. In the circuit, we use op-amp (IC741) to amplifying $1 \mathrm{~V}$ to $5 \mathrm{~V}$. We interface the temperature sensor to the PIC16F877A microcontroller using the ADC port on the microcontroller [10].

The LM35 series are precision integrate-circuit temperature sensors whose output voltage is linearly proportional to the
Celsius temperature [7]. The LM35 thus has an advantage over linear temperature sensors calibrated in ${ }^{\circ}$ Kelvin, as the user is not required to subtract a large constant voltage from its output to obtain convenient Centigrade scaling [8].

Temperature $\left({ }^{\circ} \mathrm{C}\right)=\operatorname{Vout}\left(100{ }^{\circ} \mathrm{C} / \mathrm{V}\right)$

So if Vout is $1 \mathrm{~V}$, then, temperature $=100{ }^{\circ} \mathrm{C}$. The output voltage varies linearly with temperature.

\section{PCB DESIGN}

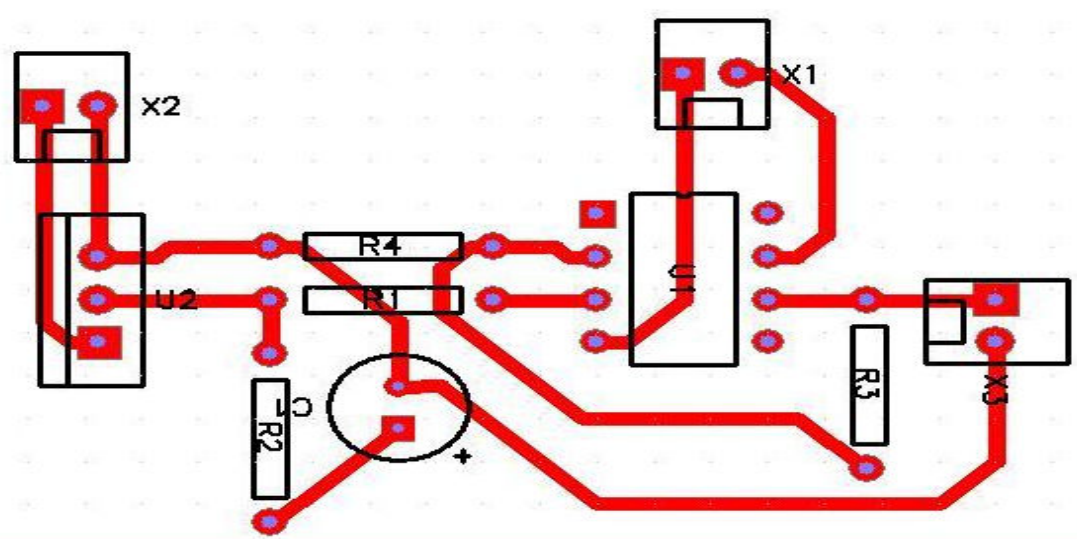

Fig 5: PCB Design for Temperature sensor

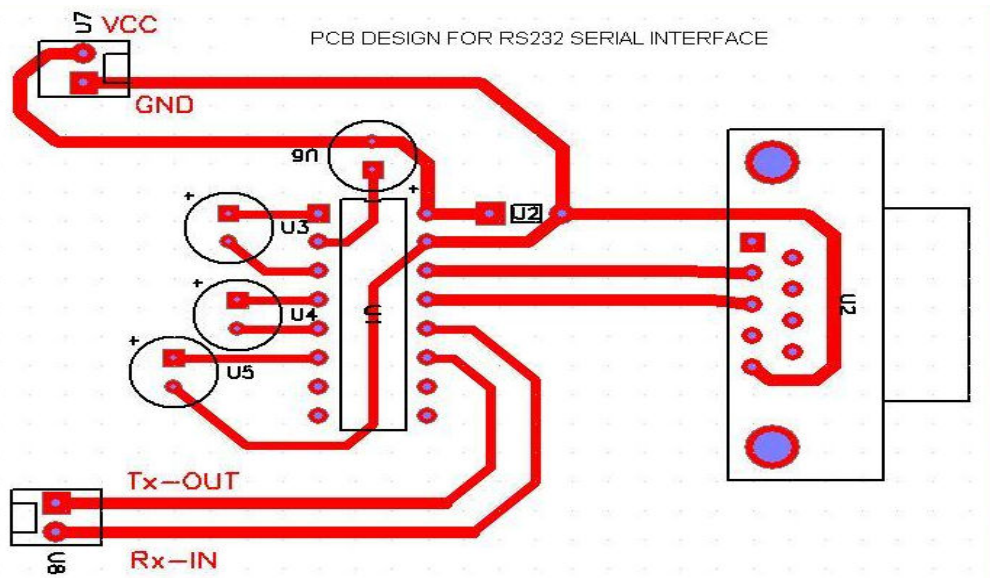

Fig 6: PCB Design for RS232 Serial Interface 


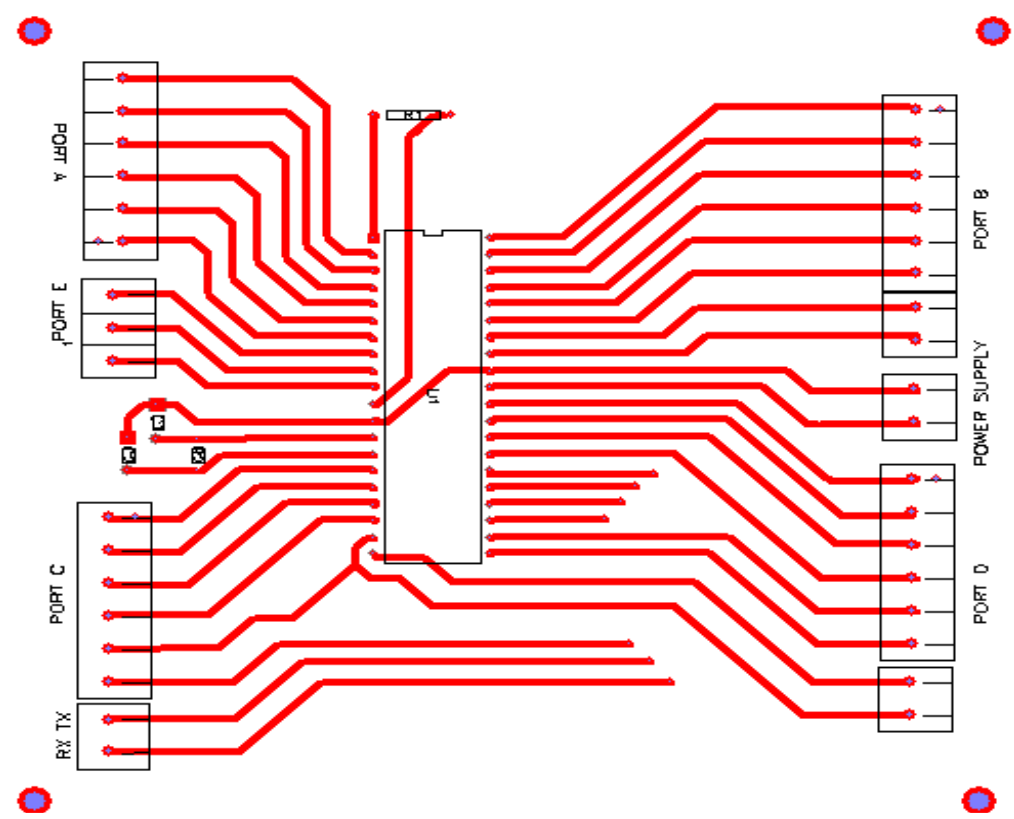

Fig 7: PCB Design for PIC Microcontroller

\section{CONCLUSION}

The temperature sensor (LM 35) is connected to PIC microcontroller and varying temperatures is sent to GSM modem which is simultaneously displayed in LCD and also send as message. Through this experiment and implementation we came to know that the temperature can be monitored using LM35 (temperature sensors) and can be send as SMS to mobile successfully.

\section{RESULT AND DISCUSSION}

GSM based temperature monitoring system is a microcontroller based project and it can be extended. We can monitor the temperature and also can be controlled in future. Temperature cannot be monitored in areas where we cannot monitor the conditions directly and manually. Not only by monitoring and sending temperature by SMS but also can be controlled and make the system to off. The system can be controlled and monitored via Short Message Service (SMS) from anywhere that covered by GSM (Global System for Mobile Communication) service.

\section{ACKNOWLEDGEMENT}

We gratefully acknowledge the financial support from the council of DST-PURSE, Bharathiar University.

\section{REFERENCE}

[1] Baburao Kodavati, V.K.Raju, S.Srinivasa Rao, A.V.Prabu, T.Appa Rao, Dr.Y.V.Narayana "GSM and GPS based vehicle location and tracking system” IJERA Vol. 1 Issue 3, pp.616-625.

[2] Malik Sikandar Hayat Khiyal, Aihab Khan, and Erum Shehzadi, "SMS Based Wireless Home Appliance Control System (HACS) for Automating Appliances and Security" Informing Science and Information Technology Volume 6,2009

[3] Konstantinos Perakis, Konstantinos Banitsas, Georgios Konnis, Dimitris Koutsouris, "3G Networks in Emergency Telemedicine - An In-Depth Evaluation \&Analysis",
Proceedings of the 2005 IEEE Engineering in Medicine and Biology 27th Annual Conference Shanghai, China, September 1-4, 2005

[4] Mrs.RamyaKulandaivel, P.Ponmalar, B.Geetha, G.Saranya "GPS AND GSM BASED VEHICLE INFORMATION SYSTEM" International Journal of Communications and Engineering Volume 01- No.1, Issue: 01 March2012

[5] Dr.B.Ramamurthy1 S.Bhargavi2 Dr.R.ShashiKumar "Development of a Low-Cost GSM SMS-BasedHumidity Remote Monitoring and Control system for Industrial Applications" IJACSA Vol. 1, No. 4, October 2010.

[6] Goswami, T. Bezboruah and K.C. Sarma, "Design of an Embedded System for Monitoring andControlling Temperature and Light", International Journal of Electronic Engineering ResearchVolume 1 Number 1 (2009) pp. 27-36.

[7] S.Josephine selvarani "online health monitoring systems using zigbee" IJCSE vol.3 No.4 Apr 2011.

[8] Ushasree.K, Hameed Pasha (Asst.Prof) "Protection system for VIP'S with GPRS \&Remote monitoring" International Journal of Computer Trends and Technology- volume2 2011.

[9] Serhat YILMAZ, Burak TOMBALOGLU, Kursat KARABULUTLU, Yener GUMUS, Hasan DiNCER "Temperature control applications by means of a PIC16f877 Microcontroller".

[10] Sanjay Verma, Namit Gupta “ Microcontroller-based Wireless Heart Rate Telemonitor for Home Care" IOSR Journal of Engineering Volume 2, Issue 7(July 2012), PP $25-31$

[11] syam krishna, j.ravindra " Design And Implementation Of Remote Home Security System Based On Wsns And Gsm Technology” IJESAT Jan-Feb 2012. 
[12] Ritesh Gupta, Mukti Awad, "pic controller based process control system using gsm”, volume 1,Issue 5,july 2012.

[13] R. Balaji, R. Ganesan, "Remote Water Pollution Monitoring System Using GSM" International Journal of Computer Science and its Applications.
[14] Amit Sachan, "Microcontroller Based Substation Monitoring and Control System with GSM Modem" IOSR Journal of Electrical and Electronics Engineering 2012.

[15] Amit Sachan, "GSM based SCADA monitoring and control system substation equipment".International Journal of Engineering Research \& Technology 2012. 